ВОРОНЦОВ Сергей Алексеевич - доктор юридических наук, профессор кафедры процессуального права Южно-Российского института - филиала Российской академии народного хозяйства и государственной службы при Президенте РФ (344002, Россия, г. Ростов-на-Дону, ул. Пушкинская, 70; raven_serg@mail.ru)

ПОНЕДЕЛКОВ Александр Васильевич - доктор политических наук, профессор; заведующий кафедрой политологии и этнополитики Южно-Российского института - филиала Российской академии народного хозяйства и государственной службы при Президенте РФ (344002, Россия, г. Ростовна-Дону, ул. Пушкинская, 70; ропеdelkov@uriu.ranера.ru); заслуженный деятель науки РФ

\title{
АНАЛИЗ ПРОБЛЕМ МЕСТНОГО УПРАВЛЕНИЯ В УСЛОВИЯХ ГЛОБАЛЬНЫХ ВЫЗОВОВ
}

Аннотация. В статье на основе результатов социологического исследования анализируются проблемы местного самоуправления в условиях санкционного давления и экономического кризиса. Авторы формулируют вывод, что в подобных условиях роль местного самоуправления существенно возрастает, позволяя держать в сфере своего внимания решение большого числа местных задач.

Ключевые слова: местное самоуправление, социологическое исследование, падение уровня жизни, демография, ресурсы

A нализ проблем местного самоуправления является традиционным направлением для Южно-Российского института управления - филиала РАНХиГС при Президенте РФ (далее - ЮРИУ РАНХиГС), и в этом отношении можно говорить о сложившейся продуктивной научной традиции. Наши ученые в тесном контакте с практическими работниками местного самоуправления регулярно исследуют проблемы, возникающие в данной сфере, в самых различных временных и социально-политических контекстах.

В декабре 2018 - феврале 2019 г. в рамках подготовки научно-практической конференции с международным участием «Местное самоуправление в условиях глобальных вызовов современной России» (г. Ростов-на-Дону; г. Азов, 04-05 апреля 2019 г.; г. Карачаевск, 10 апреля 2019 г.; г. Пятигорск, 12 апреля 2019 г.; г. Курган, 20 апреля 2019 г.; г. Челябинск, 25 апреля 2019 г.) лабораторией проблем повышения эффективности государственного и муниципального управления ЮРИУ РАНХиГС на территории 10 субъектов РФ (Ростовская, Московская, Челябинская обл., Краснодарский, Ставропольский, Камчатский края, республики Кабардино-Балкария, Северная Осетия - Алания, Коми, Карелия) был проведен социологический опрос экспертов, в котором приняли участие 2329 чел.

К социологическому опросу, проведенному в Ростовской обл., были привлечены 520 экспертов из числа руководителей представительных органов власти $(7,69 \%)$, руководителей органов исполнительной власти $(6,54 \%)$, представителей органов местного самоуправления $(18,46 \%)$, представителей научного сообщества (ученые и преподаватели) $(13,65 \%)$, руководителей общественных организаций и СМИ, культуры, неправительственных организаций $(12,68 \%)$, руководителей школьных, дошкольных образовательных и медицинских учреждений $(30,77 \%)$, представителей крупного и среднего бизнеса (10\%).

Возрастной состав опрошенных: до 25 лет - 1,15\%; от 26 до 30 лет - 2,69\%; от 30 до 39 лет - 20,38\%; от 40 до 49 лет - 34,42\%; от 50 до 59 лет - 29,23\%; 60 лет и старше - $12,12 \%$.

Стаж работы респондентов: до 5 лет - 17,12\%; от 5 до 10 лет - 20,00\%; от 10 до 20 лет - 33,08\%; от 20 до 30 лет - 20,77\%; свыше 30 лет - 9,04\%. 
Представленные экспертами оценки приведены в процентах от реального числа ответов. По отдельным позициям опроса экспертам предлагалось выбрать не более 3 определений из числа предложенных, поэтому общая сумма ответов не равна $100 \%$.

Результаты социологического опроса в Ростовской обл. показали, что более $40 \%$ экспертов отметили улучшение качества работы органов местного самоуправления в течение последних 5 лет; $31 \%$ опрошенных считают, что органы местного самоуправления достигли ощутимых результатов; не заметили принципиальных изменений за указанный период $17 \%$ экспертов. Таким образом, $88 \%$ экспертов считают, что качество работы органов местного самоуправления за последние 5 лет не только не ухудшилось, но и возросло. Число экспертов, отметивших ухудшение показателей работы органов власти на местном уровне $(2,5 \%)$, не превышает погрешности измерения. Около $4 \%$ экспертов затруднились с ответом.

В исследовании был сделан акцент на состоянии местного самоуправления в условиях глобальных вызовов. Так, более половины экспертов считают, что современный экономический кризис и антироссийские санкции лишь отчасти повлияли на функционирование системы местного самоуправления. Еще $23 \%$ опрошенных вообще не заметили влияния негативных факторов. И лишь $16 \%$ экспертов полагают, что кризис и санкционная политика Запада в значительной мере сказались на функционировании системы местного самоуправления.

Следующий вопрос фактически вытекал из указанного выше: «Если экономический кризис оказывает влияние на местное самоуправление, то в чем это конкретно проявляется?»

В числе конкретных проявлений экономического кризиса в качестве первой ранговой позиции эксперты указали заметное падение уровня жизни, рост бедности населения, снижение покупательной способности (49,81\%).

Вторую позицию занимают проблемы в демографической сфере, выражающиеся в том, что люди боятся заводить детей из-за опасения ухудшения уровня жизни, возможности потерять работу и т.п. (39,04\%). Проблемы в демографической сфере усугубляются в связи с переездом местных жителей в другие регионы или за границу в поисках более благоприятных социальных и экономических условий $(21,73 \%)$.

В качестве третьей позиции эксперты отметили существенные затруднения в экономическом развитии предприятий, расположенных на территории муниципального образования, и дополнительные проблемы с привлечением инвестиций $(25,38 \%)$.

На этом фоне лишь 14,23\% экспертов высказали мнение, что в условиях кризиса и санкционного давления началась активная мобилизация ресурсов и получен новый импульс к развитию.

При формулировании вопросов социологического исследования авторы планировали рассмотреть местное самоуправление, его характеристики, проблемы и перспективы его развития и функционирования в системе глобальных вызовов современной России и, что особенно важно в современных условиях, в контексте решения демографических проблем.

При всей важности иных аспектов демографическая ситуация имеет для будущего страны в целом и каждого отдельного региона, города, поселка принципиальное и стратегическое значение. Конечно же, муниципальный уровень не предполагает реализацию глобальной стратегии и решение макроэкономических вопросов, но позволяет отметить, какие меры респонденты считают эффективными для качественного изменения демографической ситуации на 
муниципальном уровне. Поэтому очередной вопрос касался изменений демографической ситуации за последние 5 лет в условиях кризиса.

Около половины экспертов отметили, что за последние 5 лет демографическая ситуация ухудшилась как в стране и регионе, так и в муниципальном образовании. При этом вызывает обеспокоенность, что оценки ухудшения демографической ситуации в муниципальном образовании более чем на $10 \%$ превышают оценки по стране и региону. При этом около $20 \%$ экспертов не отметили какие-либо изменения, а $15 \%$ нашли позитивные изменения. Более $20 \%$ экспертов затруднились с ответом при оценке ситуации в стране и регионе, $10 \%$ - с ответом на данный вопрос по ситуации в муниципальном образовании.

Следующий вопрос логически следовал из предыдущего: «В чем заключаются, на Ваш взгляд, основные препятствия для успешной реализации мер государственной демографической политики в регионе?»

На первую ранговую позицию в числе основных препятствий для успешной реализации мер государственной демографической политики в регионе эксперты поставили состояние стресса и неуверенности в завтрашнем дне, боязнь создать большую семью в этих условиях (60,96\%). В качестве второй позиции эксперты указали нехватку бюджетного финансирования $(58,27 \%)$.

Часть экспертов связали препятствия для успешной реализации мер государственной демографической политики в регионе с нежеланием самих граждан менять свой образ жизни, репродуктивные установки $(42,31 \%)$.

Экспертам нужно было ответить на вопрос: «Какие направления улучшения демографической ситуации в России являются наиболее реальными и практически реализуемыми на уровне общегосударственной демографической стратегии и институциональных мер?»

В качестве первой позиции эксперты ожидаемо указали повышение рождаемости коренного населения России $(73,46 \%)$. Вторую позицию заняло сокращение смертности населения России (70\%). На третьей позиции уверенно расположилось прекращение утечки населения за рубеж $(41,54 \%)$.

Стимулирование въезда иностранцев в Россию на постоянное жительство и привлечение квалифицированных работников из-за рубежа получили $5 \%$ и $6,35 \%$ соответственно.

Следующий вопрос потребовал от экспертов указать, какие направления улучшения демографической ситуации в России они считают наиболее реальными и практически реализуемыми на уровне конкретных «точечных» мер.

На первую ранговую позицию эксперты поставили значительное повышение денежных выплат от государства даже за рождение первого ребенка $(62,50 \%)$. Вторым по значимости названо увеличение выплат по программам материнского капитала и расширение возможностей для его использования $(57,31 \%)$. На третьей позиции - предоставление бесплатного жилья многодетным семьям $(52,50 \%)$.

Если добавить необходимость дополнительной поддержки многодетных семей в плане предоставления льгот по социальному обеспечению, то есть льготный трудовой стаж, дополнительное пенсионное обеспечение $(37,88 \%)$ и развитие системы нефинансовой адресной социальной помощи в виде дополнительных образовательных или медицинских услуг (25\%), то становится предельно ясным, что в качестве ключевого аспекта улучшения демографической ситуации эксперты видят финансовую поддержку многодетных семей. Объективные факторы дополняются недостатками в организации информационных кампаний в поддержку ценностей семьи и материнства, о чем свидетельствует мнение экспертов по данному вопросу (20,38\%).

Для оценки проблем, существующих в работе органов местного самоуправ- 
ления, экспертам было предложено ответить на вопрос: «Какие полномочия органов местного самоуправления в настоящее время не реализуются в полной мере?»

На первую позицию эксперты поставили ответ: полномочия в сфере дорожного строительства и организации дорожного движения $(45,38 \%)$. Вторую строку эксперты отдали полномочиям сфере ЖКХ и социально-культурного благоустройства $(36,15 \%)$. На третьей позиции - полномочия в сфере электро-, тепло-, газо-, водоснабжения (20,77\%).

Эксперты также не удовлетворены реализацией полномочий в организации досуга граждан $(16,15 \%)$, оказании услуг по сбору и вывозу бытовых отходов и мусора $(16,92 \%)$, а также в сфере решения демографических проблем $(16,73 \%)$. Следует отметить данные экспертами позитивные оценки реализации полномочий органов местного самоуправления в сфере обеспечения охраны общественного порядка, пожарной безопасности и участия населения в МСУ.

В числе причин, по которым отдельные полномочия органов местного самоуправления не реализуются должным образом, эксперты указали отсутствие достаточных материально-финансовых ресурсов $(74,42 \%)$; бюрократизм, бумаготворчество, волокиту $(24,23 \%)$; недостаточность человеческих трудовых ресурсов в связи с тяжелой демографической ситуацией: мало трудоспособного населения, мало молодежи $(23,08 \%)$.

При оценке факторов, оказывающих негативное влияние на уровень доверия населения к местным органам власти, эксперты на первую позицию поставили низкий авторитет всех органов власти у населения $(37,50 \%)$, что не может не вызывать обоснованную тревогу государства и общества. На второй позиции - формализм в работе депутатов представительного органа местного самоуправления $(27,69 \%)$, что отчасти подтверждает мнение экспертов, изложенное выше. Оторванность местных органов власти от интересов и нужд граждан $(23,65 \%)$ замыкает тройку лидирующих ответов.

Экономический кризис и попытки международной изоляции РФ не просто проверяют на прочность государство и общество, но и актуализируют вопрос о том, какие направления должны быть приоритетными для модернизации местной власти и повышения ее эффективности в условиях необходимости быстрого принятия и реализации управленческих решений. При ответе на данный вопрос на первое место эксперты поставили оптимизацию налоговой базы и укрепление муниципального бюджета $(49,42 \%)$, далее следует создание более благоприятных условий для привлечения в местные органы власти высокопрофессиональных кадров $(45,19 \%)$, укрепление кадрового потенциала муниципального управления $(26,15 \%)$.

Важность совершенствования социальных технологий активизации деятельности населения в процессе реализации проектов развития поселений отмечают только $15,58 \%$, при этом развитие независимого гражданского контроля и независимых от руководства муниципалитетов отмечают всего лишь 2,50\%. Участие жителей муниципалитетов в реальном управлении муниципальными образованиями остается низким, но это может рассматриваться как результат объективных процессов и состояния самого гражданского общества. Граждане скорее готовы участвовать в протестных акциях, если они чем-то недовольны в муниципальном управлении, но они не готовы организовываться для развития своего города или поселка, превентивного решения различных вопросов и улучшения качества и комфортности жизни.

Анализ мнений экспертов показывает, что существует социальный запрос на повышение ответственности муниципальных служащих и укрепление исполнительной дисциплины $(16,92 \%)$, борьбу с бюрократизмом $(16,54 \%)$, антикорруп- 
ционное очищение аппарата $(8,65 \%)$. Но эти результаты одновременно показывают и то, что по данным направлениям достигнуты определенные результаты и острота проблем в принципе снята.

При ответе на вопрос: «Кто должен играть ведущую роль в решении проблем местного самоуправления в условиях современных реформ и политических процессов в России?» - эксперты отдали первую позицию государству $(36,92 \%)$ и лишь потом следуют «сами люди» $(30 \%)$ и общественные организации $(20,96 \%)$.

Настораживает, что эксперты не видят правящую элиту в роли лидера решения проблем местного самоуправления в России (всего 6,92\%). Это подтверждает низкий уровень доверия к органам власти, отраженный в приведенных выше оценках экспертов.

В этой связи интерес представляют ответы экспертов на вопрос: «Что бы Вы рекомендовали предпринять в целях повышения эффективности местного самоуправления?»

На первое место эксперты поставили проблему обеспечения органов местного самоуправления достаточными финансовыми ресурсами для исполнения полномочий $(81,15 \%)$. В качестве второй позиции эксперты выделили необходимость более активно совершенствовать правовые основы местного самоуправления и предоставить органам местного самоуправления большую самостоятельность $(41,92 \%)$.

В качестве последующих позиций эксперты указали необходимость активнее привлекать население к решению вопросов местного значения $(41,92 \%)$ и вкладывать больше средств в программы, способствующие увеличению рождаемости в муниципальном образовании (39,04\%).

Подводя итог изложенному выше, необходимо отметить, что в происходящем процессе реформирования муниципальной системы в России существуют проблемы, снижающие общую эффективность функционирования органов муниципального управления и затрудняющие их эффективную модернизацию. Серьезной проблемой является зависимость муниципальных органов управления, особенно в средних и малых городах, а также в сельских поселениях, от региональных управленческих структур и их интересов. По данной причине муниципальная власть воспринимается большинством населения лишь в качестве низового подразделения региональной и государственной власти. Местное самоуправление в современных условиях, как правило, адаптируется к государственной власти и вместе с ней сохраняет нужные власти ценностные и поведенческие образцы. Местная власть функционально создает условия для приемлемости жизни населения и участвует в процессе восприятия существующих в обществе правил в области отношений власти и общества.

Важную роль в деятельности органов местного самоуправления играет проблема кризиса доверия, проявляющаяся в современных управленческих практиках и отношениях. На муниципальном уровне данное положение проявляется особенно остро, поскольку проблемы наиболее приближены к конкретным жизненным интересам населения. В то же время ограниченность ресурсов муниципалитетов требует для решения насущных проблем объединения усилий всех граждан, что невозможно без укрепления доверия [Козырева, Смирнов 2010]. Здесь доверие выступает основой совместных действий и сотрудничества, при том что в локальных сообществах отсутствие доверия и лояльности со стороны местного населения может парализовать практически любые начинания местной власти. Местная власть, со своей стороны, может также блокировать действия со стороны местного сообщества, решая свои ситуационные 
проблемы и сохраняя стабильность, но утрачивая доверие населения и снижая его готовность принимать участие в любых начинаниях власти.

Современная функциональная составляющая деятельности органов местного самоуправления основана на реализации задач по отношению к местному сообществу как объекту управленческого воздействия. Здесь принципиально важно то, что государство не в состоянии решать все вопросы и следить за всеми процессами и тем более своевременно на них реагировать при усложнении социального организма с его нестабильностью и необходимостью постоянного ситуационного реагирования на возникающие проблемы. Поэтому роль местного самоуправления в условиях экономического кризиса существенно возрастает, позволяя держать в сфере своего внимания решение большого числа местных задач.

\section{Список литературы}

Козырева П.М., Смирнов А.И. 2010. Доверие и его роль в консолидации российского общества. - Социальные факторы консолидации Российского общества: социологическое измерение (под ред. М.К. Горшкова). М.: Новый хронограф. C. 160-199.

VORONTSOV Sergei Alekseevich, Dr.Sci. (Legal), Professor of the Chair of Procedural Law, South-Russian Institute - Branch of the Russian Presidential Academy of National Economy and Public Administration (70 Pushkinskaya St, Rostov-on-Don, Russia, 344002; raven_serg@mail.ru)

PONEDELKOV Aleksandr Vasil'evich, Dr.Sci. (Pol.Sci.), Professor; Head of the Chair of Political Science and Ethnopolitics, South-Russian Institute - Branch of the Russian Presidential Academy of National Economy and Public Administration (70 Pushkinskaya St, Rostov-on-Don, Russia, 344002; ponedelkov@uriu.ranepa.ru); Honored Scientist of the Russian Federation

\section{AN ANALYSIS OF LOCAL GOVERNANCE PROBLEMS IN THE CONTEXT OF GLOBAL CHALLENGES}

Abstract. Based on the results of a sociological study, the article analyzes the problems of local self-government in the context of sanctions pressure and economic crisis. The authors conclude that in such conditions the role of local selfgovernment increases significantly, allowing to keep a large number of local problems in the attention.

Keywords: local government, sociological research, decline in living standards, demography, resources 